\title{
Physical activity in Sahara Moroccan hemodialysis patients
}

\author{
A. Bahadi ${ }^{1,3^{*}}$, H. Lagtarna 4 , S. Benbria 1 , Y. Zajjari ${ }^{1,3}$, D. Elkabbaj ${ }^{1,3}$ and N. Zemraoui ${ }^{2,4}$
}

\begin{abstract}
Objective: The evaluation of physical activity for chronic hemodialysis patients is a new approach for patient global care. The objective of this work is to evaluate the physical activity in chronic hemodialysis patients and identify the risk factors associated with reduced physical activity. This is a prospective study for 6 months including 150 chronic hemodialysis patients in the Guelmim-Oued Noun Regionin Moroccan Sahara. We use Baecke's survey, translated and validated in Arabic local language. The socio-demographic, clinical, and biological data were completed during the interrogation and from the medical records of the patients.

Results: The mean age of our patients was $54.6 \pm 16.4$ years, with male predominance (59\%). Most patients have a low education level and $60 \%$ were illiterate. Hypertension was found in $54 \%$ of our patients, diabetes in $39 \%$, and cardiovascular disease in $10 \%$ of patients. Low Physical activity was associated with gender $(O R=4.05)$, age $(O R=1.03)$ and high education level $(\mathrm{OR}=0.2)$. Our work has met the various pre-established objectives, however other more specific studies must be conducted to better characterize the profile of physical activity in chronic hemodialysis patients.
\end{abstract}

Keywords: Hemodialysis, Physical activity, Sahara, Morocco, Education

\section{Introduction}

The prevalence of end-stage renal disease (ESRD) treated with hemodialysis (HD) is increasing dramatically worldwide. In Morocco, the number of hemodialysis patients was around 7000 patients in 2008 while in December 2018 this number reached 30,000 patients according to the Moroccan society of nephrology [1, 2]. HD has completely transformed the course of chronic renal failure by improving patient survival and quality of life. However, HD is still associated with high morbidity and mortality, including the reduction of autonomy and physical activity. In this context, several studies have shown the benefit of maintaining or resuming physical activity on the health of chronic hemodialysis patients [3-6].

\footnotetext{
*Correspondence: bahadiali@gmail.com

${ }^{1}$ Department of Nephrology, Dialysis and Kidney Transplantation, Military

Teaching Hospital Mohammed Vth, Rabat, Morocco

Full list of author information is available at the end of the article
}

Physical activity is defined by the world health organization as any bodily movement produced by skeletal muscles that require energy expenditure [7]. Popular ways to be active are through walking, cycling, sports, recreation, and can be done at any level of skill and for enjoyment. This includes movements made while working, playing, doing household chores, moving around, and during leisure activities. Baecke developed in the Netherlands a questionnaire for evaluating physical activity and separating it into three representative indices: the work activity index, the sports activity index, and the index leisure activity [8]. This survey was validated as a PA assessment tool by many authors [9].

The objective of our study was to analyze the level of physical activity in chronic hemodialysis patients in Moroccan Sahara and to identify the risk factors for reduced physical activity in this area. The region Guelmim has 433,757 inhabitants, $65 \%$ of whom are urban with 9.4 inhabitants / $\mathrm{km} 2$ of density and it

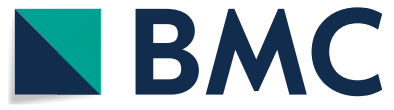

(C) The Author(s) 2021. This article is licensed under a Creative Commons Attribution 4.0 International License, which permits use, sharing, adaptation, distribution and reproduction in any medium or format, as long as you give appropriate credit to the original author(s) and the source, provide a link to the Creative Commons licence, and indicate if changes were made. The images or other third party material in this article are included in the article's Creative Commons licence, unless indicated otherwise in a credit line to the material. If material is not included in the article's Creative Commons licence and your intended use is not permitted by statutory regulation or exceeds the permitted use, you will need to obtain permission directly from the copyright holder. To view a copy of this licence, visit http://creativeco mmons.org/licenses/by/4.0/. The Creative Commons Public Domain Dedication waiver (http://creativecommons.org/publicdomain/ zero/1.0/) applies to the data made available in this article, unless otherwise stated in a credit line to the data. 
contains four provinces: Guelmim, Sidi Ifni, Tan-Tan and Assa Zag,

\section{Main text Methods}

It is a prospective descriptive-analytical study spread over 6 months, from April 2019 to October 2019. This study involved a cohort of 150 hemodialysis patients in all hemodialysis centers in the Guelmim-Oued-Noune region:

- Hemodialysis Center of the Military Hospital at Guelmim (27 patients)

- Hemodialysis center of the Guelmim regional hospital (60 patients)

- Guelmim private hemodialysis center (32 patients)

- Sidi Ifni hemodialysis center (20 patients)

- Assa Hemodialysis Center (5 patients)

- Tan-Tan hemodialysis center (6 patients)

\section{Inclusion criteria}

we included patients on hemodialysis for more than six months, Clinically stable patients in absence of a major handicap reducing mobility (limb amputation, paraplegic, or requiring a wheelchair to move).

\section{Exclusion criteria}

we excluded patients with hearing impairment, Acute renal failure, and patients not consenting.

\section{Data collection}

The parameters likely to influence physical activity (PA) in chronic hemodialysis patients were studied. Socialdemographic data were completed during the interrogation and clinical - biological data of patients were collected from the medical files: Demographic data, Socio-professional categories, clinical data, biological parameters, and dialysis data.

\section{Physical activity}

We assessed the physical activity of our patients using the Baecke survey consisting of 16 questions. It is selfadministered, and allows in its initial form, to determine a work activity index (WAI, eight questions), a sports activity index (SAI, four questions), and a leisure activity index (LAI, four questions). An adaptation was made, which reduced the questionnaire to five questions. The answers to the first two questions determine the SAI: the combination of the intensity of the sport, its frequency of practice per week, and over the year, makes it possible to calculate the SAI. The average of the answers to the other three questions on a five-point scale allows the calculation of the leisure activity index (WAI). In our study, we studied the leisure activity of our patients (WAI). The development of the questionnaire involved several stages to adapt it to our Moroccan cultural context. The adaptation methodology we followed can be summarized as follows:

- Independent translations (from French to Moroccan Dialectal), before the summary translation which was carried out by a group of professionals representing skills in different disciplines (Nephrologists, Professors of the French language...).

- Modification of the questionnaire according to the equivalence of the Arabic Dialectal version compared to the original questionnaire on the one hand, and according to the remarks and misunderstandings of the patients who participated in the pre-test on the other hand.

- Counter-translation into French.

\section{Statistical analysis}

The descriptive analysis of clinical, socio-demographic, and biological data allowed the calculation of the absolute and relative frequencies for the qualitative variables, and the positioning and dispersion parameters for the quantitative variables (mean, standard deviation).

The normal distribution of variables was studied by the Kolmogorov-Smirnov test.

- In bivariate analysis, the comparison of continuous variables used the Student test and the Mann Whitney test. In the multivariate analysis, we used binary logistic regression.

- The significance threshold was retained for a $\mathrm{p}<0.05$.

- The statistical analysis was performed using IBM SPSS version 20.0 software.

The study respected patient anonymity and the confidentiality of medical information.

\section{Results}

The average age of our 150 included patients was $54.6 \pm 16.4$ years, with extremes ranging from 18 to 85 years, a male predominance was noted with a sex ratio of $89 \mathrm{M} / 61 \mathrm{~F}$. The demographics of our study population are summarized in Table 1.

Most patients have a low level of education and 38\% of patients have no job. $65 \%$ of patients live in an urban location, $30 \%$ are retired and $18 \%$ are students. The ministry of health paid hemodialysis for up to $61 \%$ of patients and others were covered by a social security system (employees, military...). 
Table 1 Characteristics of patients at inclusion

\begin{tabular}{ll}
\hline Caracteristics & $\mathbf{N}=\mathbf{1 5 0}$ \\
\hline Age (mean \pm Sd) years & $54.6 \pm 16.4$ \\
Male n (\%) & $89(59.3)$ \\
Co-morbodities & \\
Hypertension & $82(54.7)$ \\
Diabetes & $59(39.3)$ \\
Arteriopathy & $19(12.7)$ \\
Cardiopathy & $15(10)$ \\
Low limb fracture & $11(7.3)$ \\
Obesity & $10(6.7)$ \\
Blind & $6(4)$ \\
Depression & $4(2.7)$ \\
Neoplasm & $4(2.7)$ \\
Educational status & \\
Illiterate & $91(60.7)$ \\
Primary school & $22(14.7)$ \\
High school & $33(22)$ \\
University & $4(2.7)$ \\
Treatment & \\
Erythropoietin & $74(49.3)$ \\
Antihypertensive drug & $80(53.3)$ \\
Calcium & $101(67.3)$ \\
Dialysis data & \\
Months on hemodialysis (median; quartiles) & $48[24-96]$ \\
2 Sessions per week & $84(56)$ \\
KTN & $1.33 \pm 0.15$ \\
Biologic data & \\
Haemoglobin (mean $\pm \mathrm{ET}) \mathrm{g} / \mathrm{dl}$ & $39.8 \pm 14.6 .5][1-6]$ \\
Calcium (mean \pm ET) mg/l & $10.2 \pm 2$ \\
Phosphore (median; quartiles) & $87.8 \pm 17.6$ \\
&
\end{tabular}

\section{Clinical data}

$12 \%$ of patients have an arteriopathy and $7 \%$ have a lower limb fracture. For comorbidities, we found hypertension in 54\%, diabetes in $39 \%$, and cardiopathy in $10 \%$

\section{Physical activity}

Only $19 \%$ of patients report having regular physical and/or sporting activity (walking, football). 19\% of patients report having no physical activity and are mainly patients assisted in their daily activities by a third person. $63 \%$ of cases report difficulty performing significant physical efforts (running, lifting a heavy object). Regarding the means of transport used to get to hemodialysis centers, most of our patients $(88 \%)$ used a vehicle (car, motorbike, etc.) while only $11 \%$ came on foot.

The calculation of physical activity indices revealed the following information: in patients who practice sports, the mean sports activity index (SAI) is $0.79 \pm 0.7$. Moreover, the average leisure activity index (LAI) is $2.45 \pm 1.2$. The average of these 2 indices is equal to $1.62 \pm 0.8$ which corresponds to limited physical activity, and this in the different aspects of the daily life of our HD patients.

\section{Low Physical activity risk factors}

To search risk factors of low activity, we compare two groups: group A with low physical activity defined by a global activity index (GAI) less than 5 and group B with intermediate or high physical activity (Table 2). In the univariate analysis, we found that low activity is associated with age, female, living in a rural area, diabetes, 2 dialysis sessions by week, use of anti-hypertension drugs, and car for coming to hemodialysis center. However, after including all factors in a multivariate model only three risk factors still significant: elderly patients $(O R=1,03)$, female $(\mathrm{OR}=4,05)$, and low education level (illiterate and primary school).

\section{Discussion}

It is a prospective descriptive-analytical study that required fieldwork and a trip between all the centers in the GUELMIM-OUED NOUN region. The distance traveled during the completion of this work is estimated at $648 \mathrm{~km}$. The PA assessment was carried out using the Beacke survey and has been the focus of several studies which is considered to be one of the most reproducible $[10,13]$.

According to the literature review, the average age varies between 51.6 and 69 years. The results of our series showed an average age of 54.6 years $[8,11]$. Several series in the literature report a predominance of men, notably a local Moroccan study carried out by Karimi [14] at the Al Fârâbî hospital in Oujda with a sex ratio of $45 \mathrm{M} / 38 \mathrm{~F}$, that of Fiaccadorie [15] carried out in Italy with a percentage of $67 \%$ male, and that of Matsuzawa [16] in Japan had a male predominance of $55 \%$. This joins our study where the male sex is predominant with a percentage of $60 \%$.

During our study, it turned out that the majority of our patients had a low socioeconomic level, with a thatching rate of $38 \%$. Although the illiterate rate has decreased in Morocco thanks to programs to combat illiteracy, $61 \%$ of our population, unfortunately, was illiterate as reported by Karimi's study where the majority of patients were unemployed and illiterate [14].

Diabetes, hypertension, and cardiovascular disease are the most prevalent chronic diseases according to the literature review and were also found in our patients 
Table 2 Risk factors of low physical activity in univariate and multivariate analysis

\begin{tabular}{|c|c|c|c|c|c|c|}
\hline \multirow[t]{2}{*}{ Factor } & \multicolumn{3}{|l|}{ Univariate analysis } & \multicolumn{3}{|c|}{ Multivariate analysis } \\
\hline & Low activity $n=97$ & $\begin{array}{l}\text { Others } \\
\mathrm{N}=53\end{array}$ & $\mathrm{p}$ & OR & IC & $p$ \\
\hline Age (mean) years & 59,6 & 45,4 & $<0.001$ & 1.03 & $1-1,06$ & 0.019 \\
\hline Female n(\%) & $46(47.4)$ & $15(28.3)$ & 0.025 & 4.05 & $1.36-12$ & 0.012 \\
\hline Assurance n(\%) & $44(45.4)$ & $14(26.4)$ & 0.024 & 4.8 & $0.27-84$ & 0.27 \\
\hline Rural area n(\%) & $38(39.2)$ & $30(56.6)$ & 0.017 & 0.32 & $0.07-1.38$ & 0.12 \\
\hline Education ${ }^{a} n(\%)$ & $19(19.6)$ & $18(34)$ & 0.051 & 0.2 & $0.04-0.87$ & 0.032 \\
\hline Hypertension n(\%) & $54(55.7)$ & $28(52.8)$ & 0.8 & & & \\
\hline Diabetes n(\%) & $48(49.5)$ & $11(20.8)$ & 0.001 & 1.82 & $0.63-5.18$ & 0.26 \\
\hline $\mathrm{BMI}<25$ & $82(84.5)$ & $15(28.3)$ & 0.01 & 5.7 & $0.57-57$ & 0.137 \\
\hline Months on HD & 69.2 & 58.4 & 0.39 & & & \\
\hline 2 sessions/W n(\%) & $46(47.4)$ & $38(71.7)$ & 0.004 & 0.15 & $0.01-2.14$ & 0.16 \\
\hline KTN & 1.33 & 1.33 & 0.9 & & & \\
\hline AntiHT drugs n(\%) & $58(59.8)$ & $22(41.5)$ & 0.04 & 1.71 & $0.61-4.77$ & 0.3 \\
\hline Depression n(\%) & $2(2.1)$ & $2(3.8)$ & 0.6 & & & \\
\hline Neoplasm n(\%) & $3(3,1)$ & $1(1,9)$ & 0.6 & & & \\
\hline Erythropoietin n(\%) & $48(49.5)$ & $26(49.1)$ & 0,9 & & & \\
\hline Iron drug n(\%) & $57(58.8)$ & $22(41.5)$ & 0.06 & 1.67 & $0.64-4.35$ & 0.28 \\
\hline Calcium (mean) mg.l & 89.9 & 83.9 & 0.07 & 1.02 & $0.99-1.05$ & 0.07 \\
\hline Haemoglobin (mean) g.dl & 10.3 & 9.9 & 0.3 & & & \\
\hline Phosphore (mean) mg.l & 41,6 & 59 & 0.38 & & & \\
\hline PTHi (mean) pg.ml & 527 & 515 & 0.8 & & & \\
\hline $25 \mathrm{OH}$ vitD & 39.8 & 39.8 & 0,9 & & & \\
\hline CRP (mean) mg.l & 8.1 & 16.3 & 0,19 & & & \\
\hline Anemia n(\%) & $61(62.9)$ & $36(67.9)$ & 0.14 & & & \\
\hline Car Use ${ }^{b} \mathrm{n}(\%)$ & $93(95.9)$ & $40(75.5)$ & $<0.001$ & 2.01 & $0.41-9.79$ & 0.38 \\
\hline
\end{tabular}

a Education defined by college level and upper

b Patients using car for going to hemodialysis unit

(diabetes 39\%, hypertension 54\%). In particular, diabetes, which was the leading cause of chronic kidney disease (46\%) in our patients, followed by hypertension (25\%).

The mean duration of hemodialysis in our study was 65.41 months. The majority of our patients are on dialysis twice a week, joining the study by Karimi [14], where most of the patients were also dialyzed twice a week, with an average duration of hemodialysis of $102.4 \pm 41,9$ months.

During our study, it turned out that only $19 \%$ of patients had regular physical activity. This is due to three risk factors: gender, age and low education level.

We found that females on hemodialysis in Moroccan Sahara are at high risk of low physical activity (OR 4.05). This result is supported by some studies showing that men are more active than women [17]. This can be explained by the lack of adherence to recommended physical activity which is significantly more frequent in women as found by Hornick and al [18]. The built environment also has a positive effect on physical activity in women more than men like movability index calculated based on residential density, land use mix, street connectivity, availability of public transport, and public open spaces) [19-21]. These conditions are not yet very available in such context of Sahara.

Our study shows that elderly subjects have a decreased PA compared to the youngest subjects, which joins Karimi's study. Older patients spent up to $8 \mathrm{~h}$ a day inactive corresponding to around $80 \%$ of their waking time [22]. This can be explained by the lack of energy and fatigue reported by several elderly respondents, in addition to the chronic pain experienced by these patients. The impact of chronic pain on the quality of life of patients is currently proven by several authors [23]. Pain is responsible for discomfort in daily activity in $67 \%$ of cases [24]. This pain can be explained by amyloidosis b2 microglobulin. The presence of amyloid deposits mainly in articular and para-articular tissues (synovial membranes, tendons, ligaments) and in bones clinically cause the appearance of joint and 
peri-articular pain syndromes and ductal syndromes [25].

High education level has a positive effect on PA and educated people are more physically active and pay more attention to their health [26, 27]. Varo and al (EU study) showed that people with primary level education were more sedentary than people with higher levels of education [28]. The majority of our hemodialysis patients are illiterate (61\%) and the correlation of illiteracy with decreased PA can be explained in part by ignorance of the importance of regular physical activity in these patients. The study by Capitanini [29] carried out in Italy in 2014, showed that the lack of specific advice concerning physical exercise in nephrology establishments favored a sedentary lifestyle. This element should be taken into account especially when it comes to a low educated population.

\section{Limitations}

We use a subjective means to quantify the PA of patients and The lack of financial support did not allow us to buy pedometers to better quantify the PA of our patients. We, therefore, used the Baecke survey as a tool to assess PA. We also had Incomplete biological data in some files: During operation, KT/V was mentioned in only 32 files. Only 75 files were complete. In the 75 remaining files, the phosphocalcic balance was incomplete or completely absent.

\section{Abbreviations}

ESRD: End stage renal disease; HD: Hemodialysis; PA: Physical activity; $\mathrm{Hb}$ Haemoglobin; PTH: Parathormone; CRP: C reactive protein; WAl: Work activity index; SAI: Sport activity index; LAl: Leisure activity index; GAl: Global activity index; OR: Odds ratio.

\section{Acknowledgements}

We thank nephrologist and nurses of hemodialysis centers at Tantan, guelmim, Assa and sidi ifni in Moroccan sahara.

\section{Authors' contributions}

AB: writing and literature revue. HL: data collection. SB: data collection. YZ: statistic analysis. DE: manuscript correction. NZ: conception of study and correction.

\section{Funding}

This work has no funding support.

\section{Availability of data and materials}

Data are available any time for control and the datasets used and/or analysed during the current study available from the corresponding author on reasonable request: Bahadi Abdelaali; bahadiali@gmail.com.

\section{Ethics approval and consent to participate}

The study was carried out with respect for patient anonymity and the confidentiality of medical information. The study was approved by the Moroccan ministry of health at September the 3rd 2019 with a written consent of all participants.

\section{Consent for publication}

Not applicable.

\section{Competing interests}

Authors declare no competing interest.

\section{Author details}

${ }^{1}$ Department of Nephrology, Dialysis and Kidney Transplantation, Military Teaching Hospital Mohammed Vth, Rabat, Morocco. ${ }^{2}$ Department of Nephrology, Military Hospital Avicenne, Marrakech, Morocco. ${ }^{3}$ Faculty of Medicine and Pharmacy, University Mohammed V, Rabat, Morocco. ${ }^{4}$ Faculty of Medicine and Pharmacy, University Caddy Ayyad, Marrakech, Morocco.

Received: 20 October 2020 Accepted: 22 January 2021

Published online: 17 February 2021

\section{References}

1. Benghanem Gharbi M, Couchoud C. Epidémiologie de l'insuffisance rénale chronique et besoins en greffe dans les pays du Maghreb. Les 2èmes Journées de l'Agence de Biomédecine, 23 \& 24 Mai 2011, Paris.

2. Belghiti Alaoui A. Les maladies non transmissibles : quels défis pour le Maroc ? 8ème Congrès National de Néphrologie, 18-20 Mars 2010. Agadir.

3. Lou X, Li Y, Shen H, Juan J, He Q. Physical activity and somatic symptoms among hemodialysis patients: a multi-center study in Zhejiang, China. BMC Nephrol. 2019;20(1):477. https://doi.org/10.1186/s12882-019-1652-z (PMID:31878896;PMCID:PMC6933661).

4. Müller-Ortiz H, Pedreros-Rosales C, Vera-Calzaretta A, González-Burboa A, Zúñiga-San Martín C, Oliveros-Romero MS. Exercise training in advanced chronic kidney disease. Rev Med Chil. 2019;147(11):1443-1448. Spanish. doi: https://doi.org/10.4067/S0034-98872019001101443. PMID: 32186605.

5. Zhao J, Qi Q, Xu S, Shi D. Combined aerobic resistance exercise improves dialysis adequacy and quality of life in patients on maintenance hemodialysis. Clin Nephrol. 2020;93(6):275-82. https://doi.org/10.5414/CN110033 (PMID: 32271146)

6. Ortega-Pérez de Villar L, Martínez-Olmos FJ, Pérez-Domínguez FB, et al. Comparison of intradialytic versus home-based exercise programs on physical functioning, physical activity level adherence, and healthrelated quality of life pilot study. Sci Rep. 2020;10(1):8302. https://doi. org/10.1038/s41598-020-64372-y.

7. WHO. https://www.who.int/news-room/fact-sheets/detail/physical-activ ity

8. Baecke JAH, Burema J, Frijters ER. A short questionnaire for the measurement of habitual physical activity in epidemiological studies. Am J Clin Nutr. 1982;36:936-42.

9. Bigard AX, Duforez F, Portero P, Guezennec CY. Assessment of physical activity by questionnaire: validity of the Baecke questionnaire. Sci Sports. 1992;7:2015-221.

10. Laëtitia Vassieux, Bérénice Brès, Caroline Heuzé, Benjamin Geniaux, Gaëtan Jeudy. Ativités physiques et sportives pour la santé : Des recommandations à la pratique $2015 ; 2: 11-12$

11. Panaye M, Kolko-Labadens A, Lasseur C, Paillasseur JL, Guillodo MP, Levannier M, Teta D, Fouque D. Phenotypes influencing low physical activity in maintenance dialysis. J Ren Nutr. 2015;25(1):31-9.

12. Avesani CM, Trolonge S, Deléaval P, et al. Physical activity and energy expenditure in haemodialysis patients: an international survey. Nephrol Dial Transplant. 2012;27(6):2430-4

13. P Bacquaert, Bacquaert MA. Questionnaire d'Auto-évaluation du niveau de sédentarité-Revue de littérature. https://www.irbms.com/quest ionnaire-dauto-evaluation-du-niveau-de-sedentarite-revue-de-litteratur e/

14. Karimi I, Benabdellah N, Bentata Y, Yacoubi H, Haddiya I. Evaluation du niveau d'activité physique dans un service Marocain d'hémodialyse chronique. Pan Afr Med J. 2013;15:79.

15. Fiaccadori E1, Sabatino A, Schito F, Angella F, Malagoli M, Tucci M, Cupisti A, Capitanini A, Regolisti G. Barriers to physical activity in chronic hemodialysis patients a single-center pilot study in an Italian dialysis facility. Kidney Blood Press Res 2014;39(2-3):169-75

16. Matsuzawa R, Roshanravan B, Shimoda T, Mamorita N, Yoneki K, Harada M, Watanabe T, Yoshida A, Takeuchi Y, Matsunaga A. Physical activity dose 
for hemodialysis patients: where to begin? results from a prospective cohort study. J Ren Nutr. 2018;28(1):45-53.

17. Hornik B, Duława J. Frailty, quality of life, anxiety, and other factors affecting adherence to physical activity recommendations by hemodialysis patients. Int J Environ Res Public Health. 2019;16(10):1827.

18. Hui Kang S, Do JY, Jeong HY, Lee SY, Kim JC. The clinical significance of physical activity in maintenance dialysis patients. Kidney Blood Press Res. 2017:42:575-86

19. Tcymbal A, Demetriou Y, Kelso A, et al. Effects of the built environment on physical activity: a systematic review of longitudinal studies taking sex/gender into account. Environ Health Prev Med. 2020;25(1):75. https ://doi.org/10.1186/s12199-020-00915-z (PMID: 33246405; PMCID:

\section{PMC7697377)}

20. Panter J, Ogilvie D. iConnect C Can environmental improvement change the population distribution of walking? J Epidemiol Comm Health. 2017;71(6):528-35.

21. Brown BB, Werner CM. A new rail stop. Tracking moderate physical activity Bouts and ridership. Am J Prev Med. 2007;33(4):306-9.

22. Matthews $C E$, Chen KY, Freedson PS, Buchowski MS, Beech BM, Pate RR, et al. Amount of time spent in sedentary behaviors in the United States, 2003-2004. Am J Epidemiol. 2008;167(7):875-81.

23. Nasr M, Hadj Ammar M, Khammouma S, et al. Haemodialysis and its impact on the quality of life. Nephrol Ther. 2008;4(1):21-7.

24. Bouattar T, Skalli Z, Rhou H, Ezzaitouni F, et al. The evaluation and analysis of chronic pain in chronic hemodialysis patients. Nephrol Ther. 2009;5(7):637-41.
25. Ben Salah FZ, Dziri C, Mokni M. Douleurs ostéoarticulaires chez le dialysé chronique et médecine physique et de réadaptation. Journal de Réadaptation Médicale : Pratique et Formation en Médecine Physique et de Réadaptation. 2012;32(1):19-26.

26. Kleinke F, Penndorf P, Ulbricht S, Dörr M, Hoffmann W, van den Berg N Levels of and determinants for physical activity and physical inactivity in a group of healthy elderly people in Germany: Baseline results of the MOVING-study. PLoS ONE. 2020;15(8):e0237495.

27. Trost SG, Owen N, Bauman AE, Sallis JF, Brown W. Correlates of adults' participation in physical activity: review and update. Med Sci Sports Exerc. 2002;34(12):1996-2001.

28. Varo JJ, Martinez-Gonzalez MA, De Irala-Estevez J, Kearney J, Gibney M, Martinez JA. Distribution and determinants of sedentary lifestyles in the European Union. Int J Epidemiol. 2003;32(1):138-46.

29. Capitanini A, Lange S, D'Alessandro C, Salotti E, Tavolaro A, Baronti ME, Giannese D, Cupisti A. Dialysis exercise team: the way to sustain exercise programs in hemodialysis patients. Kidney Blood Press Res. 2014;39(2-3):129-33.

\section{Publisher's Note}

Springer Nature remains neutral with regard to jurisdictional claims in published maps and institutional affiliations.
Ready to submit your research? Choose BMC and benefit from:

- fast, convenient online submission

- thorough peer review by experienced researchers in your field

- rapid publication on acceptance

- support for research data, including large and complex data types

- gold Open Access which fosters wider collaboration and increased citations

- maximum visibility for your research: over 100M website views per year

At BMC, research is always in progress.

Learn more biomedcentral.com/submissions 